Case Report

\title{
The Charming Tale of Charm Needles!
}

\section{Sham Kishor Kanneppady', Sowmya Sham Kanneppady², Anusha Rangare Lakshman², Khoo Suan Phaik', Shishir Ram Shetty ${ }^{5}$}

${ }^{1}$ Senior Lecturer, ${ }^{4}$ Professor and Associate Dean, Division of Oral Diagnostic Sciences, School of Dentistry, International Medical University, Kuala Lumpur, Malaysia. ${ }^{2}$ Senior Lecturer and Head, Department of Pharmacology, Faculty of M edicine, Lincoln University College, Selangor, M alaysia, ${ }^{3}$ Reader, Department of Oral M edicine and Radiology, Century International Institute of Dental Science and Research Centre, Kasaragod, India, ${ }^{5}$ Assistant Professor, Department of Oral M edicine and Radiology, College of dentistry, Gulf medical University, Ajman, United Arab Emirates.

*Corresponding Author: Sham Kishor Kanneppady, Senior Lecturer, Division of Oral Diagnostic Sciences, School of Dentistry, International Medical University, Kuala Lumpur, M alaysia. E-mail : drsham.omr@gmail.com

Received

: 04.03.2017

Review Completed : 06.05.2017

Accepted

$: 18.05 .2017$

Keywords : Susuk, charm needles, spiritual healing, traditional belief, panoramic radiograph

\begin{tabular}{|c|}
\hline Access this article online \\
\hline Quick Response Code \\
\hline
\end{tabular}

\begin{abstract}
Charm needles or susuk are needle-shaped metallic objects inserted subcutaneously in different parts of the body. The practice of inserting susuk is, an indisputably cultural and superstitious traditional belief common in the south-east Asian region, especially to the people of Malaysia, Thailand, Singapore, Indonesia and Brunei. With increased use of diagnostic radiographs in dental or medical practice, the discovery of charm needles has become more frequent. We report one such case of charm needles inserted in oro-facial region which was discovered in routine dental radiograph, with emphasis on cultural and traditional belief.
\end{abstract}

\section{Introduction}

Intentional modifications of the body for non-medical reasons like aesthetic reasons, religious reasons, and to show self-expression is called body modification. Piercing, Tattooing, branding, scarification and surgical implants are few examples for body modification. Not all of them originated at the same time, while some practices have been around for thousands of years, others have just begun to gain fame in recent years. One such practice of piercing foreign objects especially in the cranio-facial region is called 'Susuk' or 'Charm needles'. Their insertion in the body is a superstitious, cultural and traditional belief, which is common in the south-east Asian region, especially to the people of M alaysia, Thailand, Singapore, Indonesia and Brunei $[1,2]$. It is usually seen in M alay M uslim women and to a lesser extent in Chinese and Indian women $[3,4]$.
Most needle-wearers wish to keep the existence of the needles a secret [5]. Unavoidably, some susuk wearers seek medical and dental treatment and this secret is revealed on the radiographs. The purpose of this article is to present a case of charm needles inserted in oro-facial region and discuss the cultural and traditional aspect of such practice.

\section{Case Report}

A 38-year-old Malaysian Chinese woman reported to a Dental Institute of M alaysia, complaining of stains over her teeth. Routine diagnostic panoramic radiograph revealed multiple linear radio-opacities of about $10 \mathrm{~mm}$ size distributed in several areas $(n=11)$ throughout the image [over the right zygomatic buttress (2), left maxillary sinus (3), cervical third of root of 16 (1), cervical third of root of 27 (1), posterior to 38 at external oblique ridge (1), below the 
apex of 33 and 34 (1), at the symphysis region close to lower border of mandible (1) and below the apex of 44 and 45 (1)] (Fig. 1). Intra oral periapical radiograph of maxillary right posterior region was taken to confirm the existence of radio-opaque objects (Fig 2 ). Its density was comparable with that of silver amalgam. On close examination of the object using magnifying glass it was observed that the material is of fine needle-shape with a broader base and pointed tapered tip (Fig. 3).

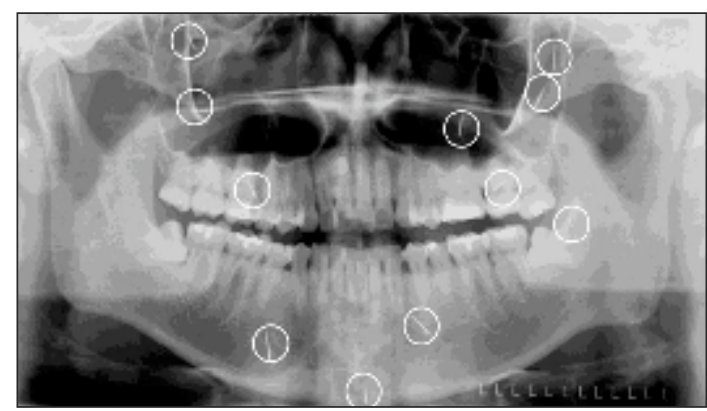

Fig. 1 : Panoramic radiograph showing multiple $(n=11)$ charm needles over the mandible, maxillary molars and maxillary sinus region (needles are highlighted with white circles).

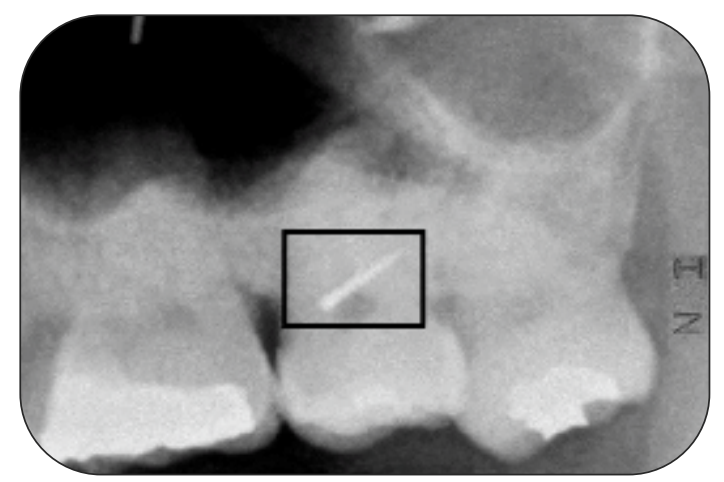

Fig. 2 : Intra oral peri apical radiograph showing charm needle over the root of 27 (needle is highlighted with black rectangle); the density of the object is comparable to that of silver amalgam restoration.

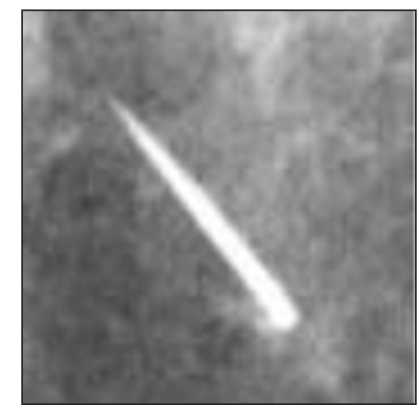

Fig. 3: Magnified image of a linear radio-opaque charm needle revealing its fine needle shape with broader base and pointed taperingtip.
After confirming the absence of any foreign objects either in the film cassette or in the film and ensuring the proper radiographic technique, the patient was interviewed regarding these multiple needle-like objects over her face. The patient hesitated to report that the insertion of small needles over her face about 10 years ago to maintain and improve her facial aesthetics. After discussing with the local staffs and considering the radiographic findings, we came to the conclusion that the needle-like objects could be charm needles or more popularly known as Susuk. On palpation of the facial tissues, the needles could not be felt. As the patient neither had any discomfort nor pain with their presence, no surgical intervention was performed. As a treatment for her complaint, oral prophylaxis was done and oral hygiene instructions were given.

\section{Discussion}

Charm needles or susuk are needle-shaped metallic objects inserted subcutaneously in different parts of the body. Unlike other types of body modifications, charm needles are not visible over the body surface. They are inserted in the body as talismans and they are assumed to improve the health and beauty of the wearer, cure headaches and joint pains, protect the wearer from hurt and accidents, improve relationship or attain success in business and career [5-7]. Charm needles are generally inserted in the cranio-facial region, and less often in other areas of the body like the breasts, chest, abdomen, limbs, spine and mons pubis [2-4, 6]. In the cranio-facial region, the most common sites for insertion are over the mandible followed by forehead, cheeks and lips [1, 4]. In the present case, the insertion was at the middle and lower third of face.

Charm needles are inserted in the soft tissues of the body by 'bomoh', also called traditional healers (who practice herbal medicine), magician, medicine man, shaman, native practitioner or Malay medicine man. Their main task is spiritual healing and prediction [1, 2, and 8]. The needles are inserted subcutaneously by gentle rubbing on the skin such that it is painless and leaves no puncture marks or blood $[1,4]$. The method used for insertion is traditionally passed down over generations. It is not sure whether 
hypnotism is used during the procedure. It is predicted that as susuk is inserted without anaesthesia, on insertion, the patient may feel pain, depending on size and shape of susuk. Some patients may come upon mild bleeding on insertion of larger susuk [2]. Susuk is usually needle or pin shaped, measuring about $0.5 \mathrm{~mm}$ in diameter and about $0.5-1.0 \mathrm{~cm}$ in length $[2,8]$.

Susuk are mostly made of gold, followed by silver and often mixed with copper. The analysis of the chemical composition found an average gold content of $89.75 \%$ and copper content of $10.25 \%[2,6]$. Gold is preferably used as it is biocompatible with tissues and noncorrosive while copper is used to increase its hardness and malleability [4, 6]. There are also other forms of talisman made of diamond and shaped by means of the normal diamond cut. Acupuncture needles can be differentiated by charm needles as they are usually longer and finer and are not normally embedded in the subcutaneoustissue.

Radiographs are the ideal diagnostic tools for confirmation of the presence of susuk. There are no reported artifacts observed in radiographs due to the presence of charm. of $A$ study by Balasundram et al [9] stated that the ultrasound imaging which was done in their patients to detect the needles was disrupted due to echo reflection and images of white striations that resembled reflective figures of metal made the localization of charm needles in the soft tissue a difficult task. Nambiar et al [3] in his study using 1.5-T M RI machine stated that charm needles showed no ferromagnetic characteristics and it was safe for patients to undergo M RI. However, it is plausible that an object that exhibits "no ferromagnetism" or weak ferromagnetic qualities in association with a 1.5-T MR system may be

\section{References}

1. Shanmuhasuntharam $P$, Ghani SH. Susuks: charm needles in facial soft tissues. Br Dent J 1991; 20: 309-311.

2. Nor MM, Yushar A, Razali M, Rahman RA, Ramli R. Incidental radiological findings of susuk in the orofacial region. Dentomaxillofac Radiol 2006; 35: 472-474.

3. Nambiar P, Ibrahim N, Tandjung YR, Shanmuhasuntharam P. Susuk (charm needles) in the craniofacial region. Oral Radiol 2008; 24: 10-15.

4. Pande S. Incidental findings of Susuk in Orthopaedic patients. Brunei Int Med J. 2011; 7 (3): 177-180.

5. SK Teo. A woman with hidden charm needles. J R Coll Physicians Edinb 2006; 36: 211-212.

6. Pothiawala S. Incidental radiological finding of charm needles. Hong Kongj.emerg.med. 2012; 19: 141-143. attracted with sufficient force to pose a hazard to an individual in an MR environment that has a magnet operating at 2.0-T or higher [9]. At present, the pertinent literature does not contain carefully controlled studies that establish the absolute safety of charm needle exposure to powerful magnetic fields.

The number of needle insertion varies. In a study of 33 susuk wearers, Nambiar et al [3] observed between 1 to 39 needles in the cranio-facial region while Oon [10] had reported between 1 to 47 susuk in a patient. Nor et al [2] reported 80 susuk noted in the face of a single patient. In our case, there were 11 charm needles in oro facial region. Susuk usually remain intact for many years but can break into smaller pieces due to corrosion and muscle contractions [5]. The threat of foreign bodies in modern day surgical practice is evident. Migration of these substances causing vascular and nerve injuries in the extremities have been reported $[7,11]$. These foreign bodies also cause increase risk of infection whether immediately upon insertion or at a later date, which requires their surgical removal. However, it is suggested that they should be left alone, unless they lead to infection or complications.

In conclusion, a wide range of surveys in literature suggests that religious, spiritual, and traditional beliefs and practices may provide positive benefits, although in some cases mixed or negative consequences to mental and physical health. There is no study done to prove that susuk placement sustains/improves facial aesthetics. But certainly, it gives a strong psychological benefit for the wearer...lifelong!

7. Rampal S, Shukur MH, Sikkandar M F. Incidental radiological finding of charm needles in the hip region: a potential surgical precaution. J Intercult Ethnopharmacol 2012; 1(1): 66-67.

8. Loh FC, Yeo JF. Talisman in the oro-facial region. Oral Surg Oral Med Oral Pathol 1989; 68: 252-255.

9. Balasundram S, Chong Mei Yee S, Shanmuhasuntharam P. Susuk: Charm needles in orofacial soft tissues. Open Journal of Stomatology 2013; 3: 155-162.

10. Oon CL. Correspondence: charm needles. Med J Malaysia 1973; 27 231-232.

11. Teo LL, Seto KY, Chai P, Venkatesh SK. Embolised injection needle fragment to the heart, mimicking a subcutaneous charm needle. Ann Acad M ed Singapore. 2010; 39: 499-500. 